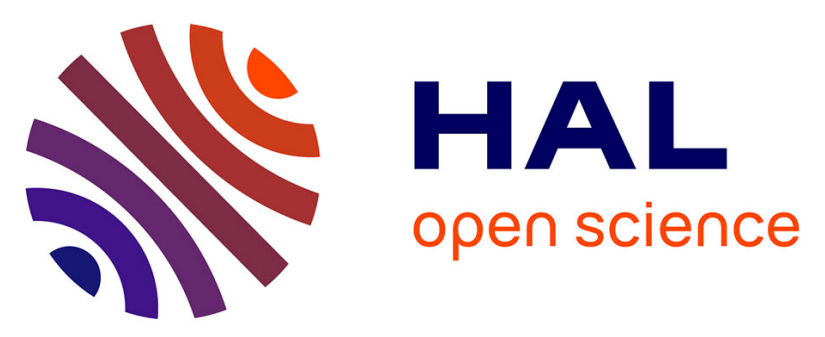

\title{
Tuning of the enzyme ratio in a neutral redox convergent cascade: A key approach for an efficient one-pot/two-step biocatalytic whole-cell system
}

Sidiky Ménil, Jean-Louis Petit, Elise Courvoisier-Dezord, Adrien Debard, Virginie Pellouin, Thomas Reignier, Michelle Sergent, Valérie Deyris, Katia Duquesne, Véronique de Berardinis, et al.

\section{To cite this version:}

Sidiky Ménil, Jean-Louis Petit, Elise Courvoisier-Dezord, Adrien Debard, Virginie Pellouin, et al.. Tuning of the enzyme ratio in a neutral redox convergent cascade: A key approach for an efficient one-pot/two-step biocatalytic whole-cell system. Biotechnology and Bioengineering, 2019, 116 (11), pp.2852-2863. 10.1002/bit.27133 . hal-03064469

\section{HAL Id: hal-03064469 \\ https://hal.science/hal-03064469}

Submitted on 14 Dec 2020

HAL is a multi-disciplinary open access archive for the deposit and dissemination of scientific research documents, whether they are published or not. The documents may come from teaching and research institutions in France or abroad, or from public or private research centers.
L'archive ouverte pluridisciplinaire HAL, est destinée au dépôt et à la diffusion de documents scientifiques de niveau recherche, publiés ou non, émanant des établissements d'enseignement et de recherche français ou étrangers, des laboratoires publics ou privés. 


\section{Tuning of the enzyme ratio in a neutral redox convergent cascade: A key approach for an efficient one-pot/two-step biocatalytic whole-cell system.}

Sidiky Ménil ${ }^{1}$, Jean-Louis Petit ${ }^{2}$, Elise Courvoisier-Dezord ${ }^{1}$, Adrien Debard $^{2}$, Virginie Pellouin ${ }^{2}$, Thomas Reignier $^{1}$, Michelle Sergent ${ }^{3}$, Valérie Deyris ${ }^{1}$, Katia Duquesne ${ }^{1}$, Véronique de Berardinis ${ }^{2}$, Véronique Alphand ${ }^{1}$

${ }^{1}$ Aix Marseille Univ, CNRS, Centrale Marseille, iSm2, Marseille, France.

${ }^{2}$ Génomique métabolique, Genoscope, Institut François Jacob, CEA, CNRS, Univ Evry, Université Paris-Saclay, 91057 Evry, France

3 Aix Marseille Univ, Univ Avignon, CNRS, IRD, IMBE, UMR 7263, Marseille, France

$\mathrm{KD}, \mathrm{VdB}$, and VA should be considered joint senior authors 
Abstract: The efficiency of a versatile in vivo cascade involving a promiscuous alcohol dehydrogenase, obtained from a biodiversity search, and a Baeyer-Villiger monooxygenase was enhanced by the independent control of the production level of each enzyme to produce $\varepsilon$-caprolactone and 3,4dihydrocoumarin. This goal was achieved by adjusting the copy number per cell of $E$. coli plasmids. We started from the observation that this number generally correlates with the amount of produced enzyme and demonstrated that an in vivo multi-enzymatic system can be improved by the judicious choice of plasmid, the lower activity of the enzyme that drives the limiting step being counter-balanced by a higher concentration. Using a preconception-free approach to the choice of the plasmid type, we observed positive and negative synergetic effects, sometimes unexpected and depending on the enzyme and plasmid combinations. Experimental optimization of the culture conditions allowed us to obtain a complete conversion of cyclohexanol $(16 \mathrm{mM})$ and 1-indanol $(7.5 \mathrm{mM})$ at a $0.5-\mathrm{L}$ scale. The yield for the conversion of cyclohexanol was $80 \%$ ( $0.7 \mathrm{~g}$ e-caprolactone, for a productivity of $\left.244 \mathrm{mg} . \mathrm{L}^{-1} \cdot \mathrm{h}^{-1}\right)$ and that for 1 -indanol $60 \%\left(0.3 \mathrm{~g}\right.$ 3,4-dihydrocoumarin, for a productivity of $\left.140 \mathrm{mg}^{\mathrm{L}} \mathrm{L}^{-1} \cdot \mathrm{h}^{-1}\right)$.

Keywords: Biocatalysis, Baeyer-Villiger Monooxygenase, Dehydrogenase, Neutral redox system, Enzymatic cascade 


\section{Introduction}

Multi-enzymatic reaction cascades are attracting growing interest in biocatalysis (Lopez-Gallego \& Schmidt-Dannert, 2010; Muschiol et al., 2015; Ricca, Brucher, \& Schrittwieser, 2011; Schrittwieser, Velikogne, Hall, \& Kroutil, 2017; Xue \& Woodley, 2012). In a "one-pot" system, they avoid the timeconsuming, waste-generating, and yield-reducing isolation and purification of intermediates, consequently resulting in the considerable saving of energy and solvents. They can also offer significant advantages directly related to yield improvement. The consumption of intermediates as they are formed avoids their accumulation and maintains concentrations that are sufficiently low to avoid many inhibitory phenomena, frequently observed with enzymes (Schrittwieser et al., 2017). In addition, the association of reversible reactions with at least one that is irreversible can result in an equilibrium shift to drive quantitative conversion.

As reviewed by Schrittwieser et al. (2017), various cascade models can be implemented depending on the chosen synthetic strategy and enzymatic features: a straightforward linear cascade (one product is the substrate for the next reaction in a sequential mode) or bi-enzymatic recycling cascade (a linear cascade involving a first enzyme that recycles the cofactor used in the second reaction, and vice versa), an orthogonal model (another enzyme eliminates undesired intermediates or participates in cofactor recycling), or parallel interconnected cascades (distinct reactions are coupled via the common use of cofactors or co-substrates) with, among them, cofactor self-sufficient cascades (Hummel \& Gröger, 2014; Schrittwieser et al., 2017). The format of the biocatalyst must then be chosen (Lopez-Gallego \& Schmidt-Dannert, 2010). Isolated enzymes, acellular extracts, or whole cells can all be considered. Furthermore, it must be decided whether the enzymes will be produced separately or together in one microorganism. The most attractive solution from an economic and practical point of view is the in vivo production of all the enzymes in a single culture, within the same organism. However, many studies have shown that this situation is often difficult to control and optimize (France, Hepworth, Turner, \& Flitsch, 2017; Ladkau, Schmid, \& Bühler, 2014; Milker, Fink, et al., 2017; Pennec, Hollmann, Smit, \& Opperman, 2015). One of the main bottlenecks is the control of the enzyme ratio. Indeed, in a multireaction system, the slowest reaction is the limiting step, driving the overall rate of the system. System performance can be improved by modifying the relative amount of each catalyst to equilibrate the rates of each step and avoid the accumulation of toxic intermediates. This is generally achieved by increasing 
the concentration of the limiting reagent. Nevertheless, although much effort has been invested in increasing the amount of enzymes produced (Park, Lee, Kim, Park, \& Oh, 2015), little work has been carried out on the rational control of the relative amounts of the different enzymes, even though this parameter is essential for improving in vivo biocatalytic multi-step processes.

Here, we report the marked improvement in the efficiency of an in vivo cascade by independently tuning the production level of each enzyme, with the lower activity of the enzyme driving the limiting step counter-balanced by a higher concentration. This goal was achieved by the judicious but unexpected choice of E. coli plasmids of various copy number per cell (PCN), a number often correlated with the amount of produced enzyme. We applied this strategy to the synthesis of $\varepsilon$-caprolactone, an important building block of polymers (Labet \& Thielemans, 2009), and 3,4-dihydrocoumarin, a natural compound widely used as a flavoring in the food industry (Häser, Wenk, \& Schwab, 2006). We designed a neutral redox cascade involving an alcohol dehydrogenase $(A D H)$ and a Baeyer-Villiger Monooxygenase (BVMO), starting from the corresponding alcohols, with the ADH found through a biodiversity screen for its unusual but necessary low enantioselectivity toward racemic 1-indanol.

Faced with unexpected empirical results, we thoroughly investigated the consequences of plasmid combinations on plasmid copy number, enzyme production, and cascade activity. We show that, in practice, the best combination with the medium-PCN pET plasmid is not, as would be expected, a highPCN plasmid, such as pRSF, revealing probable interference between plasmid replication origins. We also demonstrate that system activity is controlled by the enzyme ratio. Finally, we carried out yield optimization via a design of experiments (DOE) of the system expression conditions, resulting in optimal overall transformation.

\section{Materials and methods}

\section{Chemicals and materials}

Oligonucleotide primers were purchased from Invitrogen, Phusion® HF DNA polymerase, restriction enzymes and T4 DNA ligase were obtained from New England Biolabs. Plasmid preparation kit, PCR purification and gel extraction kits were, respectively, from Qiagen (Venlo, NL) and Promega (Madison, US). Media components were available from BD Biosciences. All other chemicals (solvents, organic substrates, standards, antibiotics, nicotinamide cofactors, isopropyl- $\beta$-D-thiogalactopyranoside (IPTG)) 
were purchased from Sigma-Aldrich, Fisher Scientific and Acros Organics in reagent or bioreagent grade.

\section{Enzymes, plasmids and strains}

Gene corresponding to $\mathrm{ADH}_{\text {Singulis }}$ (Uniprot ID: LODIZ2) and BVMOParvi (Uniprot ID: A7HU16) (Reignier et al., 2014) were amplified by PCR, with primers listed in Supporting Information Table S1. All overexpressions of selected genes were performed in E. coli BL21(DE3) (Novagen). All strains and plasmid combinations and constructions were resumed onto Table 1 and Supporting Information Table S2.

\section{Culture conditions}

Starter cultures of $E$. coli BL21 (DE3) transformants were grown aerobically overnight at $37^{\circ} \mathrm{C}$ in LuriaBertani (LB) medium (10g/L tryptone, $5 \mathrm{~g} / \mathrm{L}$ yeast extract, $10 \mathrm{~g} / \mathrm{L} \mathrm{NaCl}$ ) supplemented with appropriate antibiotics. Production cultures, in Terrific Broth (TB) medium (5 g/L glycerol, 12 g/L tryptone, $24 \mathrm{~g} / \mathrm{L}$

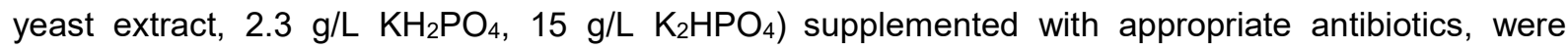
inoculated at the $\mathrm{OD}_{600}$ value of 0.1 . Growth was performed in rotary shakers at $25^{\circ} \mathrm{C}$ and $180 \mathrm{rpm}$. The protein expression was induced by adding IPTG at a final concentration of $0.5 \mathrm{mM}$ when the $\mathrm{OD}_{600}$ value reached $0.8-1.0$. The cells were further incubated at $16^{\circ} \mathrm{C}$ and $180 \mathrm{rpm}$ for $18 \mathrm{~h}$.

\section{Whole-cell biotransformations}

After growth, the equivalent of $15 \mathrm{mg} C D W$ of cells were harvested by centrifugation $\left(3,000 \mathrm{~g}, 4^{\circ} \mathrm{C}, 15\right.$ $\min )$ and the pellet was washed with potassium phosphate buffer $(0.1 \mathrm{M}, \mathrm{pH} 7)$. Cells were resuspended in $10 \mathrm{~mL}$ of potassium phosphate buffer $(0.1 \mathrm{M}, \mathrm{pH}$ 7) and transferred into a $100 \mathrm{~mL}$ baffled flask (Duran $®$ ). Whole cell biotransformations were performed at $25^{\circ} \mathrm{C}$ and $200 \mathrm{spm}$ in a longitudinal bath shaker. $3 \mathrm{mM}$ of substrate was added as an ethanolic solution (1M). Sample of $0.5 \mathrm{~mL}$ were taken over time and extracted with $0.5 \mathrm{~mL}$ of standard solution $(0.5 \mathrm{~g} / \mathrm{L}$ decane or undecane in ethyl acetate for cyclohexanol or indanol biotransformation respectively). After vortexing and centrifugation, concentrations and yields were determined by GC analysis of the organic phase on an Equity $₫-5$ column $\left(0.25 \mu \mathrm{m} \times 0.25 \mathrm{~mm} \times 30 \mathrm{~m}\right.$, Supelco) at $80^{\circ} \mathrm{C}$ or $110^{\circ} \mathrm{C}$ respectively for cyclohexanol and indanol experiments. The biocatalyst activity is the initial rate of lactone formation calculated on the first hour of the biotransformation. 
The enantioselectivity ratio (E value) of the indanol oxidation was calculated from conversion ratio (c), and indanol ee (eep) according to the formula:

$$
E=\ln [1-c(1+\text { ee } p)] / \ln [1-c(1-\text { ee } p)]
$$

Conversion and ee were obtained by GC monitoring of the biotransformation of racemic indanol by E. coli $\mathrm{pET} 22 \mathrm{~b}$-adh. Samples were analyzed on an Hydrodex $\mathrm{Y}$-DiMOM column $(0.25 \mu \mathrm{m} \times 0.25 \mathrm{~mm} \times$ $30 \mathrm{~m}$ Macherey-Nagel) according the temperature program: $90^{\circ} \mathrm{C}$ for $15 \mathrm{~min}, 100^{\circ} \mathrm{C}\left(1^{\circ} \mathrm{C} / \mathrm{min}\right)$ for 10 $\min , 110^{\circ} \mathrm{C}\left(1^{\circ} \mathrm{C} / \mathrm{min}\right)$ for $2 \mathrm{~min}$ and $150^{\circ} \mathrm{C}\left(5^{\circ} \mathrm{C} / \mathrm{min}\right)$ for $2 \mathrm{~min}$.

\section{Expression profile by SDS-PAGE and protein quantification analysis}

After growth of the transformants, samples $(0.3 \mathrm{mg} \mathrm{CDW})$ were harvested $\left(5,000 \mathrm{~g}, 4^{\circ} \mathrm{C}, 5 \mathrm{~min}\right)$ and the pellets were stored at $-80^{\circ} \mathrm{C}$ until analysis and cell disruption. Each sample was then resuspended into $20 \mu \mathrm{L}$ of DNAse I buffer ( $1 \mathrm{x})$ and treated by DNAse I $(5 \mathrm{U})$ for $15 \mathrm{~min}$ at $25^{\circ} \mathrm{C}$ then heated at $90^{\circ} \mathrm{C}$ for 3 min after adding $40 \mu \mathrm{L}$ of Laemmli buffer (2x) (containing $400 \mathrm{mM}$ DTT), $5 \mu \mathrm{L}$ of SDS $10 \%(\mathrm{~m} / \mathrm{m})$ and $15 \mu \mathrm{L}$ of distillated water. The soluble fractions (6 $\mu \mathrm{L}$, equivalent to $22.5 \mu \mathrm{g} \mathrm{CDW})$ were analysed by SDS-PAGE. For the sake of comparison, all samples were analysed simultaneously on a single gel of $0.75 \mathrm{~mm}$ thickness revealed by Coomasie blue staining before to be photographed on UVITEC Imager Alliance 9.7 as a 8-bit image. The spots, defined with the polygon selection tools, were integrated with the ImageJ software (https://imagej.nih.gov/ij) after optical density calibration using the Rodbard (NIH) curve fitting method. After background subtraction and load normalisation, the enzyme amounts were estimated by comparison with the spots of purified BVMO and ADH corresponding to a respective amount of 1.24 and $1.25 \mu \mathrm{g}$ per well.

\section{Quantitative PCR (qPCR)}

Six genes were targeted and amplified using the specially designed set of primers (using Primer3 Manager software) described in Supporting Information Table S3. The housekeeping gene rpoB (RNA polymerase $\beta$ subunit gene) was used as probe for $E$. coli genomic DNA, the three genes corresponding to the antibiotic resistance cassette of each plasmid and the two genes encoding for the ADH and BVMO were targeted to calculate independently each PCN. 
qPCR conditions: for each experiment, a volume equivalent of $0.6 \mathrm{mg} . \mathrm{CDW}$ of cells was centrifuged. The pellet was resuspended in a double volume of PBS $1 \times \mathrm{pH}$ 7.4. Cells were lysed by $95^{\circ} \mathrm{C}$ incubation for 10 minutes, followed by a series of dilutions of up to $10^{-6}$ times. Each sample was immediately freezed at $-20^{\circ} \mathrm{C}$. Simultaneously $4 \mu \mathrm{l}$ suspension of lysed cells in a dilution range from $0.6 .10^{-2}-0.610^{-5}$ mg.CDW/ $\mu$ l was amplified using qPCR Master Mix (2x) (LightCycler® 480 SYBR Green I Master) and both set of primers in a concentration of $0.5 \mu \mathrm{M}$ each, in separated reactions. The qPCR conditions were 10 min at $95^{\circ} \mathrm{C}$ then 40 cycles of $15 \mathrm{~s}$ at $95^{\circ} \mathrm{C}, 30 \mathrm{~s}$ at $60^{\circ} \mathrm{C}$ and $10 \mathrm{~s}$ at $72{ }^{\circ} \mathrm{C}$.

Data analysis: data obtained were analyzed for Tm calling, determination of primer efficiency, using LightCycler® 480 software. Primer efficiency was calculated by plotting the correlation of cycle threshold (Ct) to log DNA template concentration, giving the equation $y=B x+A$. Primer efficiency was obtained using the equation $E=10(-1 / B)$. Good primer efficiency ranged between 1.85 to 2.05 as described by Dorak (Dorak, 2006). The correlation of $\mathrm{Ct}$ to log cell number was plotted to determine the ratio of plasmid to chromosome per cell $(\mathrm{P} / \mathrm{C})$ based on the equation:

$$
\frac{\text { number of Plasmid }(P)}{\text { bnumber of chromosome }(C)}=\frac{E c^{C t c}}{E p^{C t p}}
$$

with Ec=rpoB efficiency targeting chromosome, Ep=efficiency of the targeting plasmid or bvmo or adh gene, $\mathrm{Ctc}_{\mathrm{c}}=\mathrm{Ct}$ of $r p o \mathrm{~B}$ targeting chromosome, $\mathrm{Ctp}=\mathrm{Ct}$ of the targeting plasmid or bvmo or adh gene.

The PCNs measured by the mean of the antibiotic resistance gene or the targeted gene were of the same magnitude (less than $20 \%$ variation) (Supporting Information Table S7). Thus, the quantification of the antibiotic resistance genes is a suitable method to get the copy number of a plasmid or a targeted gene without the need to redesign and reoptimize specific primers and amplification assay: the primers and assays we set up may be used as universal quantitative analysis methods for any construction with ampicillin, kanamycin or chloramphenicol resistance genes.

\section{Experimental design for culture optimization}

Strain, harboring pRSF-adh and pET-bvmo plasmids, was chosen for optimization. Cell culture and whole-cell biotransformations conditions were described above unless modifications directed by the DOE. To determine the most significant factors among the nine presented Table 2, a two-level Hadamard design with 12 experiments (Supporting Information Table S9) was used and the experimental response was the overall activity of the bi-enzymatic whole cell system. The data were 
reported in Supporting Information Table S10 and analysed by NemrodW $®$ software (LPRAI, Marseille, France).

In order to determine the best values of the two most relevant factors previously selected (duration and temperature after induction), an empirical mathematical model was used, which establishes the relationship between the variation of the response (activity) and the variation of the factors $X$. This quadratic model is $\eta=\beta_{0}+\beta_{1} X_{1}+\beta_{2} X_{2}+\beta_{11} X_{1}^{2}+\beta_{22} X_{2}^{2}+\beta_{12} X_{1} X_{2}$ where $\eta$ represents the variation of the responses; $\beta_{0}$ is the constant factor; $\beta_{\mathrm{i}}, \beta_{\mathrm{ii}}$ and $\beta_{\mathrm{ij}}$ are the coefficients of the linear, quadratic and cross-product terms, respectively. The composite matrix of 12 experiments is described Supporting Information Table S11. The values of temperature after induction were 15,20 or $25^{\circ} \mathrm{C}$ and those of induction period were 8,16 or $24 \mathrm{~h}$. The values of the other parameters were set as reported Table 2 in bold.

\section{Results and discussion}

\section{Selection of enzymes of the neutral redox cascade}

The in vivo two-enzymes system we used to synthesize $\varepsilon$-caprolactone and 3,4-dihydrocoumarin from cyclohexanol and indanol, respectively, was composed of an ADH and a BVMO. ADHs are often NAD+or, more rarely, $\mathrm{NADP}^{+}$-dependent enzymes that ensure the reversible transformation of alcohols in ketones (Kallberg, Oppermann, \& Persson, 2010). BVMOs irreversibly oxidize ketones in esters and lactones. The BVMO mechanism is close to that of chemical Baeyer-Villiger oxidation via the formation of a reactive peroxyflavine, with reducing equivalents brought by the cofactor NADPH or, more rarely, NADH (Leisch, Morley, \& Lau, 2011). We eliminated the influence of cofactor recycling (which could be a limiting parameter) on our system efficiency by using a self-sufficient cofactor cascade called "closedloop" based on the pioneering model described first by Willetts (Figure 1) and then more recently by several other authors, as reviewed by (Hummel \& Gröger, 2014). In this situation, the two enzymes have to be respectively $\mathrm{NADP}^{+}$and NADPH dependent to ensure the reciprocal role of recycling the enzyme cofactor.

Several multi-step enzymatic syntheses of $\varepsilon$-caprolactone have been previously designed (Bornadel, Hatti-Kaul, Hollmann, \& Kara, 2015; Huang et al., 2017; Mallin, Wulf, \& Bornscheuer, 2013; Oberleitner et al., 2013; Oberleitner, Peters, Rudroff, Bornscheuer, \& Mihovilovic, 2014), with varying levels of success, whereas the biocatalytic synthesis of 3,4-dihydrocoumarin from 1-indanol has never been 
described. A major constraint in the selection of the enzymes within a cascade system is obviously the need of compatible substrates, the product of one being the substrate of the other. The choice is large for $\varepsilon$-caprolactone formation but more restricted for dihydrocoumarin synthesis.

Only a few native or mutated Type I BVMOs, essentially NADPH-dependent enzymes, are known to transform 1-indanone into 3,4-dihydrocoumarin (Fill, da Silva, de Oliveira, da Silva, \& Rodrigues-Fo, 2012; Gutiérrez, Alphand, \& Furstoss, 2003; Rioz-Martínez, de Gonzalo, Torres Pazmiño, Fraaije, \& Gotor, 2010). Finally, we chose the promiscuous BVMO ${ }_{\text {Parvi }}$ from the previously characterized bacteria Parvibaculum lavamentivorans DS-1 (Reignier et al., 2014), which can oxidize both cyclohexanone and 1-indanone. This strictly NADPH-dependent BVMO differs from other Type I BVMOs in its ability to transform $\alpha, \beta$-unsaturated ketones into enol-lactones, as described previously (Reignier et al., 2014).

Although several bioreductions of 1-indanone (Endo et al., 2016; Fill et al., 2012) or biooxidations of 1indanol (Martin et al., 2006; Pennacchio, Giordano, Pucci, Rossi, \& Raia, 2010; Pennacchio et al., 2008; Zhang, Tang, Wang, \& Li, 2011) are mentioned in the literature, none of the involved enzymes could be used in this study, because these enzymes were shown to be either highly enantioselective or $\mathrm{NAD}^{+}-$ dependent. Ideally, a NADP+-linked dehydrogenase with low (if any) enantioselectivity is needed to ensure cofactor recycling and complete transformation of the racemic indanol.

We found such a non-enantioselective ADH that was efficient for both substrates by diversity screening of an $\mathrm{NADP}^{+}$-dependent $\mathrm{ADH}$ collection. This collection was built by a sequence-driven approach (Vergne-Vaxelaire et al., 2013) using the cyclohexanol dehydrogenase ChnA (Uniprot Id: Q7WVD1) from Acinetobacter sp. NCIMB 9871(Iwaki, Hasegawa, Teraoka, \& Tokuyama, 1999) and the cyclopentanol dehydrogenase CpnA (Uniprot Id: Q8GAV9) from Comamonas sp. NCIMB 9872 (Iwaki, Hasegawa, Wang, Kayser, \& Lau, 2003) as a reference. We cloned approximately 180 genes into the expression vector pET22b-type following the same methodology described previously by (VergneVaxelaire et al., 2013). The proteins were over-expressed in E. coli strain BL21(DE3). Screening was performed on cell lysates by monitoring the disappearance of $\mathrm{NADP}^{+}$by spectrophotometry at $340 \mathrm{~nm}$ using cyclohexanol and racemic 1-indanol as substrates. From this collection, 31 enzymes were able to significantly oxidize cyclohexanol and 18 also 1-indanol (Supporting Information Table S4). From these active enzymes, we selected an uncharacterized protein from Singulisphaera acidiphilia (Uniprot ID: LODIZ2, $A D H_{\text {singulis }}$ ), with only a predicted short-chain, zinc-independent, dehydrogenase/reductase 
(SDR) family signature, for its ability to efficiently use both substrates. $\mathrm{ADH}_{\text {singulis }}$ shares $47 \%$ identity with chnA from Acinetobacter and 36\% with CpnA from Cacomonas. We then cloned the gene with a HisTag at the $\mathrm{N}_{\text {term }}$ and the protein was over-expressed and purified by nickel affinity to determine its specific activity against both substrates and kinetic parameters (Supporting Information Table S5). We explored the substrate scope of this newly-characterized ADH by testing various linear and saturated or unsaturated cyclic substrates bearing primary and secondary alcohols (Supporting Information Table S5), showing high promiscuity, with the best catalytic efficiency for cycloheptanol $\left(\mathrm{k}_{\text {cat }} / \mathrm{K}_{\mathrm{m}}=1353\right.$ $\left.\mathrm{s}^{-1} \cdot \mathrm{mM}^{-1}\right)$. The catalytic efficiency for 1-indanol and cyclohexanol were found to be similar, approximately $850 \mathrm{~s}^{-1} \cdot \mathrm{mM}^{-1}$. Enantioselectivity was determined using racemic indanol oxidation in whole-cell experiments with E. coli cells over-expressing $\mathrm{ADH}_{\text {singulis }}(E$. coli $\mathrm{pET} 22 \mathrm{~b}-\mathrm{adh}$ ). The enantiomeric ratio was very low $(E<5)$ and enabled complete reaction of a racemic mixture of indanol. The kinetic parameters of $\mathrm{BVMO}_{\text {Parvi }}$ against cyclohexanone and 1-indanone were lower (catalytic efficiency of 26 and $15 \mathrm{~s}^{-1} \cdot \mathrm{mM}^{-1}$, respectively) (Supporting Information Table S6).

\section{Effect of the stoichiometric ratio on in vitro and in vivo system activity:}

We investigated the effect of the enzyme stoichiometric ratio in vitro (mixtures of both purified enzymes in various ratios), as well as in vivo (mixtures of $E$. coli $\mathrm{pET} 22 \mathrm{~b}$-adh cells producing ADH with $E$. coli pET22b-bvmo cells producing BVMO) on caprolactone. The more BVMO there was relative to ADH, the

greater the measured activity (the initial $\varepsilon$-caprolactone formation rate), confirming the rate-limiting role of BV oxidation (data not shown). This latter experiment highlighted another advantage of using cascades. Cells of $E$. coli pET22b-adh failed to significantly oxidize cyclohexanol into cyclohexanone, probably due to an equilibrium that strongly favors reduction in whole cells. However, the subsequent irreversible BV oxidation of the ketone intermediate was able to overcome this unfavorable equilibrium, even under conditions of mixed cells (data not shown), a situation in which $\mathrm{NADP}^{+}$recycling cannot occur.

\section{Systematic construction and comparison of the co-expressing strains}

Heterologous protein expression in bacteria, such as E. coli, has become a very attractive way to produce proteins, quickly and at low cost, as well as in whole-cell biocatalysts. Good enzyme production depends on i) the choice of culture conditions (Phillips, Park, \& Huber, 2000), ii) recombinant strain 
design (Marschall, Sagmeister, \& Herwig, 2017; Rosano \& Ceccarelli, 2014; Terpe, 2006) i.e. the E. coli strain derivative, the promoter type, and codon optimization (Boël et al., 2016), and iii) the genetic regulation system, such as ribosome binding sites (RBS) (Bonde et al., 2016) and untranslated regions (UTR) (Mahalik, Sharma, \& Mukherjee, 2014). Recently, in the context of an in cellulo multi-enzymatic system, the control of UTR elements has been successfully used to balance the production of enzymes (Song, Woo, Jung, Bornscheuer, \& Park, 2016). Here, we focused on another type of control based on plasmid copy number (PCN) per cell. The PCN generally influences enzyme production, although complex regulatory mechanisms may affect this observation (Kerrigan, Xie, Ames, \& Lu, 2011; Terpe, 2006). Although PCN has been exploited to increase protein expression (Studier \& Moffatt, 1986; Terpe, 2006), with the creation of high copy-number plasmids, little attention has focused on its use for the modulation of enzyme ratios in enzymatic-cascade systems. Indeed, recently, Chen et al. (Chen, Huang, \& Zhang, 2017) successfully investigated the co-expression of up to four enzymes in E. coli BL21(DE3) in various ratios, focusing on the influence of the $\mathrm{T7}$ promoter and terminator and the comparison of one or two plasmid systems. However, in most publications, only a small number of plasmid combinations have been tested and the best was selected empirically (Jang, Singha, Kim, Kwon, \& Park, 2016; Kohl, Srinivasamurthy, Böttcher, Kabisch, \& Bornscheuer, 2018; Müller et al., 2014; Wu et al., 2016).

We optimized the cascade by varying the copy number of the expression vector. We systematically constructed nine recombinant strains bearing both bvmoparvi and adh $h_{\text {singulis }}$ genes. We used Duet ${ }^{\mathrm{TM}}$ vectors known to result in various levels of PCN (Dustie Held \& Robert Novy, 2003) and belonging to different incompatibility groups so they could co-exist (theoretically) in the same host: pACYCDuet-1 (low copy number: $\sim 10$, ori p15A), pETDuet-1 (medium copy number: $\sim 40$, ori pBR322), and pRSFDuet1 (high copy number: $>100$, ori RSF1030). The nine strains, plus a strain bearing two empty plasmids as a control, are described in Table 3: three Duo strains (A, B and C), with both genes co-expressed in the same plasmid, and six strains (D, E, F, G, H and I) with the two genes expressed by two separate plasmids. The bvmo gene was always cloned into the second multiple cloning site (MCS2), downstream of adh in the Duo strains.

Whole-cell biotransformations of cyclohexanol with all co-expression combinations were carried out according to the protocol described in "Experimental Methods" with a substrate concentration ( $3 \mathrm{mM})$ chosen to avoid toxicity or inhibitory effects. The time-course and activity of each strain are reported in 
Figures 2 and 3A, respectively. Three groups of biocatalysts were distinguishable. The first showed moderate activity (approximately $7 \mathrm{U} / \mathrm{g} \mathrm{CDW}$ ) comprising all Duo strains (A, B, C). In this group, the activities increased from pACYC (6 U/g CDW) to pRSF (9 U/g CDW), as expected from the anticipated copy number of these plasmids. The second group showed little or no activity $(<3 \mathrm{U} / \mathrm{g} \mathrm{CDW})$ and was comprised of the F and I strains, both carrying the bvmo gene on the low copy number PACYC plasmid, as expected, as well as, surprisingly, the D strain, containing the $\mathrm{pET}$-adh and pRSF-bvmo plasmids.

Only the ketone intermediate was produced by strain I. The last group showed high activity (approximately $15 \mathrm{U} / \mathrm{g} \mathrm{CDW}$ ), displaying complete conversion in less than $5 \mathrm{~h}$ and was comprised of the $\mathrm{E}, \mathrm{H}$, and $\mathrm{G}$ strains. However, this group did not include the three stains bearing the bvmo gene on the pRSF high copy plasmid (G, D, A), as expected. Although strain $G$, containing pACYC-adh and pRSFbvmo, displayed good activity, the two other best strains were $\mathrm{H}$ and $\mathrm{E}$ bearing the bvmo gene on the $\mathrm{pET}$ vector. The most surprising results were obtained with strain $\mathrm{E}, \mathrm{E}$. coli pRSF-adh and pET-bvmo, which were the opposite of those obtained with its "mirror" D strain, bearing pET-adh and pRSF-bvmo.

We explored the impact of co-expression on plasmid copy number, estimated by qPCR, and enzyme concentrations, determined by quantitative analysis of stained SDS-PAGE gels, to obtain a better understanding of these observations (Figure 3B and $3 \mathrm{C}$ and Supporting Information Table S8).

\section{The effect of plasmid combination on plasmid copy number}

We used quantitative PCR (qPCR) (D'haene, Vandesompele, \& Hellemans, 2010; C. Lee, Kim, Shin, \& Hwang, 2006), to determine PCN, as it does not require the separation of plasmid and genomic DNA. The qPCR analyses showed a difference in the PCN per cell, depending on the recombinant cell constructs (Figure 3B and Supporting Information Table S7).

The PCN of Duo strains (harboring a single plasmid with both genes) was roughly in agreement with the literature data (low, medium, and high copies) for pACYC, pET, and pRSF, respectively. The measured PCN values in the other strains for the $\mathrm{pET}$ and $\mathrm{PACYC}$ plasmids, ranging from 30 to 50 and 10 to 20 copies, respectively, were still of the expected magnitude. In contrast to the observations of the plasmid manufacturer (Dustie Held \& Robert Novy, 2003), the pRSF PCN decreased dramatically to 5 to 10 copies in the presence of $\mathrm{pET}$ ( $\mathrm{D}$ and $\mathrm{E}$ strains), independently of the gene (D, E, and control strains). However, pRSF remained a high copy plasmid when in combination with pACYC, although there was 
an effect of the targeted gene, the PCN varying from 150 for the adh gene to 400 for the bvmo gene. An old observation of Som et al. (Som \& Tomizawa, 1982) may provide an explanation. Although pET and pRSF belong to two incompatibility groups, the authors noted relative similarity between the nucleotide sequences of the RSF1030 (pRSF replicon) and ColE1 (pET replicon) origins, which may lead to competition for their replication and thus explain the very low pRSF PCN.

Finally, our first objective of increasing the PCN ratio in favor of the bvmo harboring plasmid was achieved with the three strains $\mathrm{H}, \mathrm{E}$, and $\mathrm{G}$, which displayed PCN ratios of 3,10 , and 40 , respectively (versus a ratio $\leq 1$ for all other strains).

\section{Effect of plasmid combination on enzyme production:}

Although each MCS was preceded by its own T7 promoter and followed by a single terminator, the number of moles of the two expressed enzymes was not similar in the Duo strains, the ratio barely reaching 0.3 (in moles of monomer). This unbalanced enzyme production in favor of ADH has been previously observed in other ADH-BVMO cascades (Jang, Jeon, Baek, Lee, \& Park, 2014; Milker, Fink, et al., 2017; Müller et al., 2014) and may be due to the different size of the two enzymes, making the longer one more difficult to synthesize (Fernandes et al., 2017).

For the other strains, enzyme production did not appear to be tightly associated with plasmid level (Figure 3B and 3C, Supporting Information Figure S1). There is, however, a rational explanation if we distinguish between strains harboring the $\mathrm{pET}$ plasmid and those harboring the pRSF plasmid. There was a very good correlation, shown Supporting Information Figure S1, with PCN for the pET-containing strains. The enzyme concentration increased linearly with gene number for both enzymes. Conversely, there was an unexpected disconnection between PCN and enzyme production for the pRSF-containing strains, especially G, I, and A: bacteria with the highest number of plasmids (PCN of 400, 150, and 110, respectively) produced only a moderate amount of the corresponding enzymes (approximately 60-100 $\mathrm{mg} . \mathrm{gCW}^{-1}$ ). SDS-PAGE showed the presence of a protein of approximately $31 \mathrm{kDa}$ in all pRSF strains, which was especially intense for $G$ and I. Mass spectrometry analysis showed this protein to be the aminoglycoside 3'-phosphotransferase encoded by the kan gene, the antibiotic kanamycin resistance gene on pRSF (Supporting Information Figure S2). Its synthesis, driven by the high PCN value, clearly competed with synthesis of the targeted enzyme (Supporting Information Figure S3). Thus, the choice 
of an antibiotic resistance gene as a plasmid marker becomes a major concern for large-scale processes (Rosano \& Ceccarelli, 2014), heavily increasing the burden of overproducing strains.

\section{Effect of enzyme production on activity}

There was a loose trend linking high activity and a high amount of BVMO (Figure 4A), although several counter-examples have also been reported. Strains $\mathrm{C}$ and $\mathrm{H}$ produced a similar amount of BVMO (approximately $0.7 \mu$ mole.g $\mathrm{CDW}^{-1}$ ) but the activity produced by strain $\mathrm{H}$ was two-times higher than that produced by $\mathrm{C}$ (12 vs $\left.6 \mathrm{U.g} \mathrm{CDW}^{-1}\right)$. The trend was the opposite for $\mathrm{ADH}$. There was a much better correlation between system activity and the BVMO/ADH ratio, both increasing proportionally up to a molar ratio value of approximatively 0.5 , at which point the activity reached a plateau of approximately 14 U.g CDW-1 (Figure 4C).

Another limiting factor probably interfered, possibly the $\mathrm{NADPH} / \mathrm{NADP}^{+}$content, $\mathrm{O}_{2}$ supply, and/or the endogenous FAD content. NADPH limitation is well documented (Milker, Fink, et al., 2017) and one of the most important challenges to whole-cell processes reaching the industrial level. However, in our case, the need of NADPH, even in high-level BVMO cells, should not have exceeded the cell capacity due to the cofactor recycling inherent to the cascade. Concerning $\mathrm{O}_{2}$ availability, experiments carried out using various cell densities showed that the cells were not deprived of oxygen under our conditions: the activity of E doubled between the experiment at $15 \mathrm{mg} \mathrm{CDW}$ (our conditions) and $30 \mathrm{mg}$ CDW and then remained unchanged only after this concentration (Supporting Information Figure S6). Nevertheless, intracellular $\mathrm{O}_{2}$ uptake may not be sufficiently rapid to support high-speed transformation. This hypothesis would be in agreement with the work of Park (W.-H. Lee, Park, \& Kim, 2014), in which the overexpression of an oxygen-carrying protein (bacterial hemoglobin) in an E. coli strain improved the transformation of cyclohexanone into caprolactone. On the other hand, the FAD content of $E$. coli is roughly estimated to a few $\mu$ moles per g CDW (Hou et al., 2017), namely the same order of magnitude as the production of BVMO (Figure 4A). As suggested by Milker et al. (Milker, Goncalves, Fink, \& Rudroff, 2017), the endogenous FAD may be not enough to form the active FAD-bound BVMO, necessary to the reaction. 


\section{Optimization by design of experiments}

In spite of these limitations, we decided to optimize the best construct, strain E, following a statistical approach by design of experiments (DOE). However, instead of determining enzyme production or the enzymatic ratio, we examined the activity of the biotransformation. We focused first on the conditions of the expression step. Nine potentially influencing factors (type of inoculum, pre-culture medium, initial cell density of the culture, incubation temperature before induction, cell density at induction, IPTG concentration, stirring speed, and incubation time, as well as incubation temperature after induction) were considered to evaluate the magnitude of their effect. Thus, 12 cell cultures were carried out following two-level Hadamard matrix designs and the analysed response was the rate of caprolactone formation in cyclohexanol biotransformation (Table 2 and Supporting Information S11). The most significant differences in response were for the parameters "incubation temperature after induction" and "time of incubation after induction". A new design of nine experiments was then performed according to a composite matrix at three levels: 15,20 , or $25^{\circ} \mathrm{C}$ for incubation temperature after induction and 8,16 , or $24 \mathrm{~h}$ for time of incubation after induction (Supporting Information Table S12). The data allowed us to plot the iso-response area of the response in the experimental field. These graphic representations, in two (Supporting Information Figure S5) and three (Figure 5A), dimensions enable better visualization of the maxima response areas (from 18 to $23^{\circ} \mathrm{C}$ for incubation temperature and 14 to $20 \mathrm{~h}$ for time of incubation).

The optimized conditions, an incubation at $20^{\circ} \mathrm{C}$ for $16 \mathrm{~h}$ after induction enabled us to reach specific activities of 27-28 U.g CDW-1 vs 14-16 U.g CDW-1 using the classic conditions before optimization, i.e. an incubation at $16^{\circ} \mathrm{C}$ for $18 \mathrm{~h}$ after induction. Thus, optimization of the only two culture parameters, incubation temperature and time of induction doubled the global activity of our cellular biocatalyst. The optimized activity showed much better fitting of the new point in the linear activity/ratio correlation (Figure 5B). Surprisingly, this improvement was not due to changes in enzyme production or ratio, which were stable for all composite experiments. The most probable explanation is an improvement in the capacity of the cell to supply FAD linked to the physiological state.

\section{Caprolactone and dihydrocoumarin production}

A rapid study of the biotransformation parameters, product stability, and substrate and product inhibition allowed us to achieve the complete conversion of cyclohexanol $(16 \mathrm{mM})$ and 1-indanol $(7.5 \mathrm{mM})$ at a 
$0.5 \mathrm{~L}$ scale. The respective yields were $80 \%\left(0.7 \mathrm{~g}\right.$, with a productivity of $\left.244 \mathrm{mg} . \mathrm{L}^{-1} \cdot \mathrm{h}^{-1}\right)$ and $60 \%(0.3$ $\mathrm{g}$, with a productivity of $140 \mathrm{mg} . \mathrm{L}^{-1} \cdot \mathrm{h}^{-1}$ ), respectively. The yield of 3,4-dihydrocoumarine was reached in spite of a spontaneous hydrolysis in the reaction conditions (Gutiérrez et al., 2003) by eliminating yeast extract and using potassium phosphate buffer $(\mathrm{pH} 6)$ or TRIS/glycine buffer $(\mathrm{pH} 7,5)$ as bioconversion medium .

\section{Conclusion}

Over the last several years, studies to successfully improve whole-cell cascades based on modifications of gene regulation elements have been published. We focused on the plasmids and attempted to use their copy number to control the cascade enzyme ratio in cells. By testing various combinations, we obtained a continuum of results, ranging from the absence of a reaction to complete and rapid biotransformation, with a total turnover number of 7,100 for BVMO. We showed that i) in practice, the true copy numbers of plasmids can contradict the expectations of the use of high-copy plasmids in plasmid combinations for metabolic engineering. Thus, the PCN of a high copy plasmid, such as pRSF was very low in the presence of the pET plasmid, whereas high expression was achieved when cotransformed with the very low-copy number plasmid PACYC. ii) Enzyme production is related to the PCN, but can be hampered by the parallel production of the "antibiotic resistance" enzyme. iii) Activity is more strongly correlated with the enzyme ratio than the amount of BVMO. Nonetheless, in spite of the success of the enzyme ratio modulation approach, this study confirmed the importance of limitingfactor issues inherent to cells reported in other studies. Finally, optimization of a versatile cascade involving two enzymes that catalyze reactions using a large scope of substrates offers a generic tool for the production of various oxidized ketones from their corresponding alcohols.

Acknowledgments This work was supported by the French Agence Nationale de la Recherche (NaturaDyRe, project ANR-10-CD2I-014) and the French Ministère de l'Enseignement Supérieur et de la Recherche (Sidiky Ménil fellowships). We would like to thank COST Action CM1303 on Systems Biocatalysis and also Prof. G. lacazio for access to the AVB Platform facilities.

Conflicts of interest: The authors have declared that there are no conflicts of interest. 


\section{References}

Boël, G., Letso, R., Neely, H., Price, W. N., Wong, K.-H., Su, M., ... Hunt, J. F. (2016). Codon influence on protein expression in E. coli correlates with mRNA levels. Nature, 529(7586), 358-363. https://doi.org/10.1038/nature16509

Bonde, M. T., Pedersen, M., Klausen, M. S., Jensen, S. I., Wulff, T., Harrison, S., ... Sommer, M. O. (2016). Predictable tuning of protein expression in bacteria. Nature methods, 13, 233-236. https://doi.org/10.1038/nmeth.3727

Bornadel, A., Hatti-Kaul, R., Hollmann, F., \& Kara, S. (2015). A Bi-enzymatic Convergent Cascade for $\varepsilon$-Caprolactone Synthesis Employing 1,6-Hexanediol as a 'Double-Smart Cosubstrate'. ChemCatChem, 7(16), 2442-2445. https://doi.org/10.1002/cctc.201500511

Chen, H., Huang, R., \& Zhang, Y.-H. P. (2017). Systematic comparison of co-expression of multiple recombinant thermophilic enzymes in Escherichia coli BL21 (DE3). Applied Microbiology and Biotechnology, 101(11), 4481-4493.

D'haene, B., Vandesompele, J., \& Hellemans, J. (2010). Accurate and objective copy number profiling using real-time quantitative PCR. Methods, 50(4), 262-270. https://doi.org/10.1016/j.ymeth.2009.12.007

Dorak, M. T. (Éd.). (2006). Real-time PCR. New York: Taylor \& Francis.

Dustie Held, K. Y., \& Robert Novy. (2003). New coexpression vectors for expanded compatibilities in E. coli. inNovations, 18, 4-6.

Fill, T. P., da Silva, J. V., de Oliveira, K. T., da Silva, B. F., \& Rodrigues-Fo, E. (2012). Oxidative Potential of Some Endophytic Fungi Using 1-Indanone as a Substrate. Journal of Microbiology and Biotechnology, 22(6), 832-837. https://doi.org/10.4014/jmb.1112.12014

France, S. P., Hepworth, L. J., Turner, N. J., \& Flitsch, S. L. (2017). Constructing Biocatalytic Cascades: in Vitro and in Vivo Approaches to de Novo Multi-Enzyme Pathways. ACS Catalysis, 7(1), 710-724. https://doi.org/10.1021/acscatal.6b02979

Gutiérrez, M. C., Alphand, V., \& Furstoss, R. (2003). Microbiological transformations 52.: Biocatalysed Baeyer-Villiger oxidation of 1-indanone derivatives. Journal of Molecular Catalysis B: Enzymatic, 21(4), 231-238.

Häser, K., Wenk, H. H., \& Schwab, W. (2006). Biocatalytic Production of Dihydrocoumarin from Coumarin by Saccharomyces cerevisiae. Journal of Agricultural and Food Chemistry, 54(17), 6236-6240. https://doi.org/10.1021/jf061334w

Hou, Y., Hossain, G. S., Li, J., Shin, H.-D., Du, G., Chen, J., \& Liu, L. (2017). Metabolic engineering of cofactor flavin adenine dinucleotide (FAD) synthesis and regeneration in Escherichia coli for production of $\alpha$-keto acids: Metabolic Engineering of Cofactor Flavin Adenine Dinucleotide (FAD) Synthesis and Regeneration. Biotechnology and Bioengineering, 114(9), 1928-1936. https://doi.org/10.1002/bit.26336

Huang, L., Romero, E., Ressmann, A. K., Rudroff, F., Hollmann, F., Fraaije, M. W., \& Kara, S. (2017). Nicotinamide Adenine Dinucleotide-Dependent Redox-Neutral Convergent Cascade for 
Lactonizations with Type II Flavin-Containing Monooxygenase. Advanced Synthesis \& Catalysis, 359(12), 2142-2148. https://doi.org/10.1002/adsc.201700401

Hummel, W., \& Gröger, H. (2014). Strategies for regeneration of nicotinamide coenzymes emphasizing self-sufficient closed-loop recycling systems. Journal of Biotechnology, 191, 2231. https://doi.org/10.1016/j.jbiotec.2014.07.449

Iwaki, H., Hasegawa, Y., Teraoka, M., \& Tokuyama, T. (1999). Identification of a Transcriptional Activator (ChnR) and a 6-Oxohexanoate Dehydrogenase (ChnE) in the Cyclohexanol Catabolic Pathway in Acinetobacter sp. Strain NCIMB 9871 and Localization of the Genes That Encode Them. Applied and Environmental Microbiology, 65(11), 5158-5162.

Iwaki, H., Hasegawa, Y., Wang, S., Kayser, M. M., \& Lau, P. C. K. (2003). Cloning and Characterization of a Gene Cluster Involved in Cyclopentanol Metabolism in Comamonas sp. Strain NCIMB 9872 and Biotransformations Effected by Escherichia coli-Expressed Cyclopentanone 1,2-Monooxygenase. Applied and Environmental Microbiology, 69(4), 24142414. https://doi.org/10.1128/AEM.69.4.2414.2003

Jang, H.-Y., Jeon, E.-Y., Baek, A.-H., Lee, S.-M., \& Park, J.-B. (2014). Production of w-hydroxyundec9-enoic acid and n-heptanoic acid from ricinoleic acid by recombinant Escherichia coli-based biocatalyst. Process Biochemistry, 49(4), 617-622.

https://doi.org/10.1016/j.procbio.2014.01.025

Jang, H.-Y., Singha, K., Kim, H.-H., Kwon, Y.-U., \& Park, J.-B. (2016). Chemo-enzymatic synthesis of 11-hydroxyundecanoic acid and 1,11-undecanedioic acid from ricinoleic acid. Green Chem., 18(4), 1089-1095. https://doi.org/10.1039/C5GC01017A

Kallberg, Y., Oppermann, U., \& Persson, B. (2010). Classification of the short-chain dehydrogenase/reductase superfamily using hidden Markov models: SDR classification using HMM. FEBS Journal, 277(10), 2375-2386. https://doi.org/10.1111/j.1742-4658.2010.07656.x

Kerrigan, J. J., Xie, Q., Ames, R. S., \& Lu, Q. (2011). Production of protein complexes via coexpression. Protein Expression and Purification, 75(1), 1-14. https://doi.org/10.1016/j.pep.2010.07.015

Kohl, A., Srinivasamurthy, V., Böttcher, D., Kabisch, J., \& Bornscheuer, U. T. (2018). Co-expression of an alcohol dehydrogenase and a cyclohexanone monooxygenase for cascade reactions facilitates the regeneration of the NADPH cofactor. Enzyme and Microbial Technology, 108(Supplement C), 53-58. https://doi.org/10.1016/j.enzmictec.2017.09.003

Labet, M., \& Thielemans, W. (2009). Synthesis of polycaprolactone: a review. Chemical Society Reviews, 38, 3484-3504.

Ladkau, N., Schmid, A., \& Bühler, B. (2014). The microbial cell—functional unit for energy dependent multistep biocatalysis. Current Opinion in Biotechnology, 30, 178-189. https://doi.org/10.1016/j.copbio.2014.06.003

Lee, C., Kim, J., Shin, S. G., \& Hwang, S. (2006). Absolute and relative QPCR quantification of plasmid copy number in Escherichia coli. Journal of Biotechnology, 123(3), 273-280. https://doi.org/10.1016/j.jbiotec.2005.11.014 
Lee, W.-H., Park, E.-H., \& Kim, M.-D. (2014). Enhanced Production of $\varepsilon$-Caprolactone by Coexpression of Bacterial Hemoglobin Gene in Recombinant Escherichia coli Expressing Cyclohexanone Monooxygenase Gene. Journal of Microbiology and Biotechnology, 24(12), 1685-1689. https://doi.org/10.4014/jmb.1409.09060

Leisch, H., Morley, K., \& Lau, P. C. K. (2011). Baeyer-Villiger monooxygenases: more than just green chemistry. Chemical reviews, 111(7), 4165-4222.

Lopez-Gallego, F., \& Schmidt-Dannert, C. (2010). Multi-enzymatic synthesis. Current Opinion in Chemical Biology, 14(2), 174-183. https://doi.org/10.1016/j.cbpa.2009.11.023

Mahalik, S., Sharma, A. K., \& Mukherjee, K. J. (2014). Genome engineering for improved recombinant protein expression in Escherichia coli. Microbial Cell Factories, 13(1), 177. https://doi.org/10.1186/s12934-014-0177-1

Mallin, H., Wulf, H., \& Bornscheuer, U. T. (2013). A self-sufficient Baeyer-Villiger biocatalysis system for the synthesis of $\varepsilon$-caprolactone from cyclohexanol. Enzyme and Microbial Technology, 53(4), 283-287. https://doi.org/10.1016/j.enzmictec.2013.01.007

Marschall, L., Sagmeister, P., \& Herwig, C. (2017). Tunable recombinant protein expression in E. coli: promoter systems and genetic constraints. Applied Microbiology and Biotechnology, 101(2), 501-512. https://doi.org/10.1007/s00253-016-8045-z

Martin, H.-J., Breyer-Pfaff, U., Wsol, V., Venz, S., Block, S., \& Maser, E. (2006). Purification and Characterization of Akr1b10 from Human Liver: Role in Carbonyl Reduction of Xenobiotics. Drug Metabolism and Disposition, 34(3), 464-470. https://doi.org/10.1124/dmd.105.007971

Milker, S., Fink, M. J., Oberleitner, N., Ressmann, A. K., Bornscheuer, U. T., Mihovilovic, M. D., \& Rudroff, F. (2017). Kinetic Modeling of an Enzymatic Redox Cascade in Vivo Reveals Bottlenecks Caused by Cofactors. ChemCatChem, 9(17), 3420-3427. https://doi.org/10.1002/cctc.201700573

Milker, S., Goncalves, L. C. P., Fink, M. J., \& Rudroff, F. (2017). Escherichia coli Fails to Efficiently Maintain the Activity of an Important Flavin Monooxygenase in Recombinant Overexpression. Frontiers in Microbiology, 8, 2201. https://doi.org/10.3389/fmicb.2017.02201

Müller, C. A., Dennig, A., Welters, T., Winkler, T., Ruff, A. J., Hummel, W., ... Schwaneberg, U. (2014). Whole-cell double oxidation of n-heptane. Journal of Biotechnology, 191, 196-204. https://doi.org/10.1016/j.jbiotec.2014.06.001

Muschiol, J., Peters, C., Oberleitner, N., Mihovilovic, M. D., Bornscheuer, U. T., \& Rudroff, F. (2015). Cascade catalysis - strategies and challenges en route to preparative synthetic biology. Chem. Commun., 51(27), 5798-5811. https://doi.org/10.1039/C4CC08752F

Oberleitner, N., Peters, C., Muschiol, J., Kadow, M., Saß, S., Bayer, T., ... Bornscheuer, U. T. (2013). An Enzymatic Toolbox for Cascade Reactions: A Showcase for an in Vivo Redox Sequence in Asymmetric Synthesis. ChemCatChem, 5(12), 3524-3528. https://doi.org/10.1002/cctc.201300604

Oberleitner, N., Peters, C., Rudroff, F., Bornscheuer, U. T., \& Mihovilovic, M. D. (2014). In vitro characterization of an enzymatic redox cascade composed of an alcohol dehydrogenase, an 
enoate reductases and a Baeyer-Villiger monooxygenase. Journal of Biotechnology, 192, 393 -399. https://doi.org/10.1016/j.jbiotec.2014.04.008

Park, J.-Y., Lee, S.-H., Kim, K.-R., Park, J.-B., \& Oh, D.-K. (2015). Production of 13S-hydroxy-9(Z)octadecenoic acid from linoleic acid by whole recombinant cells expressing linoleate 13hydratase from Lactobacillus acidophilus. Journal of Biotechnology, 208, 1-10. https://doi.org/10.1016/j.jbiotec.2015.05.006

Pennacchio, A., Giordano, A., Pucci, B., Rossi, M., \& Raia, C. A. (2010). Biochemical characterization of a recombinant short-chain $\mathrm{NAD}(\mathrm{H})$-dependent dehydrogenase/reductase from Sulfolobus acidocaldarius. Extremophiles, 14(2), 193-204. https://doi.org/10.1007/s00792-009-0298-3

Pennacchio, A., Pucci, B., Secundo, F., La Cara, F., Rossi, M., \& Raia, C. A. (2008). Purification and Characterization of a Novel Recombinant Highly Enantioselective Short-Chain NAD(H)Dependent Alcohol Dehydrogenase from Thermus thermophilus. Applied and Environmental Microbiology, 74(13), 3949-3958. https://doi.org/10.1128/AEM.00217-08

Pennec, A., Hollmann, F., Smit, M. S., \& Opperman, D. J. (2015). One-pot Conversion of Cycloalkanes to Lactones. ChemCatChem, 7(2), 236-239. https://doi.org/10.1002/cctc.201402835

Phillips, G. J., Park, S.-K., \& Huber, D. (2000). High Copy Number Plasmids Compatible with Commonly Used Cloning Vectors. BioTechniques, 28, 400-408.

Reignier, T., de Berardinis, V., Petit, J.-L., Mariage, A., Hamzé, K., Duquesne, K., \& Alphand, V. (2014). Broadening the scope of Baeyer-Villiger monooxygenase activities toward $\alpha, \beta-$ unsaturated ketones: a promising route to chiral enol-lactones and ene-lactones. Chemical Communications, 50(58), 7793. https://doi.org/10.1039/c4cc02541e

Ricca, E., Brucher, B., \& Schrittwieser, J. H. (2011). Multi-Enzymatic Cascade Reactions: Overview and Perspectives. Advanced Synthesis \& Catalysis, 353(13), 2239-2262. https://doi.org/10.1002/adsc.201100256

Rioz-Martínez, A., de Gonzalo, G., Torres Pazmiño, D. E., Fraaije, M. W., \& Gotor, V. (2010). Synthesis of Chiral 3-Alkyl-3,4-dihydroisocoumarins by Dynamic Kinetic Resolutions Catalyzed by a Baeyer-Villiger Monooxygenase. The Journal of Organic Chemistry, 75(6), 2073-2076. https://doi.org/10.1021/jo902519j

Rosano, G. L., \& Ceccarelli, E. A. (2014). Recombinant protein expression in Escherichia coli: advances and challenges. Frontiers in Microbiology, 5, 172. https://doi.org/10.3389/fmicb.2014.00172

Schrittwieser, J. H., Velikogne, S., Hall, M., \& Kroutil, W. (2017). Artificial Biocatalytic Linear Cascades for Preparation of Organic Molecules. Chemical Reviews, 118(1), 270-348.

Som, T., \& Tomizawa, J. (1982). Origin of replication of Escherichia coli plasmid RSF 1030. Molecular \& General Genetics, 187(3), 375-383.

Song, J.-W., Woo, J.-M., Jung, G. Y., Bornscheuer, U. T., \& Park, J.-B. (2016). 3'-UTR engineering to improve soluble expression and fine-tuning of activity of cascade enzymes in Escherichia coli. Scientific Reports, 6, 29406. https://doi.org/10.1038/srep29406 
Studier, F. W., \& Moffatt, B. A. (1986). Use of bacteriophage T7 RNA polymerase to direct selective high-level expression of cloned genes. Journal of Molecular Biology, 189(1), 113-130.

Terpe, K. (2006). Overview of bacterial expression systems for heterologous protein production: from molecular and biochemical fundamentals to commercial systems. Applied Microbiology and Biotechnology, 72(2), 211-222. https://doi.org/10.1007/s00253-006-0465-8

Vergne-Vaxelaire, C., Bordier, F., Fossey, A., Besnard-Gonnet, M., Debard, A., Mariage, A., ... Zaparucha, A. (2013). Nitrilase Activity Screening on Structurally Diverse Substrates:

Providing Biocatalytic Tools for Organic Synthesis. Advanced Synthesis \& Catalysis, 355(9), 1763-1779. https://doi.org/10.1002/adsc.201201098

Wu, S., Zhou, Y., Wang, T., Too, H.-P., Wang, D. I. C., \& Li, Z. (2016). Highly regio- and enantioselective multiple oxy- and amino-functionalizations of alkenes by modular cascade biocatalysis. Nature Communications, 7, 11917.

Xue, R., \& Woodley, J. M. (2012). Process technology for multi-enzymatic reaction systems. Bioresource Technology, 115, 183-195.

Zhang, W., Tang, W. L., Wang, D. I. C., \& Li, Z. (2011). Concurrent oxidations with tandem biocatalysts in one pot: green, selective and clean oxidations of methylene groups to ketones. Chemical Communications, 47(11), 3284-3286. https://doi.org/10.1039/C0CC04706F 